\title{
Concentração sérica da proteína total, globulina total, gamaglobulina e IgG total de potros no nascimento aos trinta dias de vida
}

Campo Amor Vieira da Cunha Neto ${ }^{[a] "}$, Diego Jose Zanzarini Delfio ${ }^{[b]}$, Alexandre Secorun Borges ${ }^{[a]}$

\footnotetext{
[a] Faculdade de Medicina Veterinária e Zootecnia, Universidade Estadual Paulista (UNESP), Botucatu, SP, Brasil

${ }^{[b]}$ Faculdade de Medicina Veterinária, Universidade Federal de Uberlândia (UFU), Uberlândia, MG, Brasil
}

*Autor correspondente

e-mail: campoamor_vieira@hotmail.com

\section{Resumo}

Devido a placentação epiteliocorial das éguas, os potros são dependentes das imunoglobulinas colostrais. O diagnóstico de falha de transferência de imunidade passiva pode ser realizado de forma direta com imunoensaio enzimático (ELISA). Os níveis séricos de proteína total (PT), globulina total (GT) e fração gamaglobulina possuem alta correlação com níveis séricos de IgG e são utilizados com métodos auxiliares para estimar indiretamente a concentração de IgG. 0 objetivo deste trabalho de foi avaliar a concentração sérica de IgG de potros do nascimento aos trinta dias de vida, antes e após mamarem colostro e serem tratados com plasma hiperimune, além de verificar a correlação entre os níveis séricos de IgG e frações proteicas. Foram utilizadas amostras de sangue de 20 potros da raça Puro Sangue Inglês colhidas em cinco momentos: M1, logo após o nascimento e previamente à ingestão de colostro; M2, 10 h de vida; M3, 24 horas de vida (previamente à administração do plasma); M4, 48 horas de vida (24 horas após receberem 1 litro de plasma hiperimune); e M5, com 30 dias de vida. A concentração sérica de PT e albumina (bioquímica sérica), fração gamaglobulina (eletroforese) e a IgG (sanduíche ELISA) foram avaliadas. A média e desvio padrão da concentração sérica de IgG dos potros ao nascer foi de $15 \pm 8 \mathrm{mg} / \mathrm{dL}, 2.408 \pm 608 \mathrm{mg} / \mathrm{dL}$ com dez horas de vida, mantiveram-se em níveis semelhantes até 48 horas $(2.364 \pm 784 \mathrm{mg} / \mathrm{dL})$, e diminuíram significativamente aos 30 dias $(1.414 \pm 586 \mathrm{mg} / \mathrm{dL})$. Houve correlação positiva entre as concentrações séricas de IgG e PT $(r=0,76)$, GT ( $r=0,81)$ e gamaglobulina $(r=0,85)$. No M2, tanto os níveis séricos de IgG quanto da fração $\gamma$-globulina dos potros já estavam em valores máximos e não diferiram dos valores encontrados em M3 e M4. Não houve diferença significativa das concentrações de gamaglobulina e IgG séricas dos potros no M4 quando comparado com M3, ou seja, antes e após receberem o plasma. 0 plasma hiperimune não foi suficiente para aumentar significativamente os níveis de IgG dos potros em 24 horas 
pós-transfusão. A proteína total, globulinas totais e fração $\gamma$-globulina apresentam boa correlação com IgG. Dez horas pós nascimento já é possível verificar se houve transferência de imunidade passiva, possibilitando adotar medidas profiláticas e/ou terapêuticas quando necessário.

Palavras-chave: Potros. Imunidade passiva. Plasma hiperimune. 